\title{
Chronic Chest Disease in Australian Aboriginal Children
}

\author{
G. M. MAXWELL \\ From the Department of Paediatrics, University of Adelaide, Adelaide Children's Hospital, \\ North Adelaide, South Australia
}

\begin{abstract}
Maxwell, G. M. (1972). Archives of Disease in Childhood, 47, 897. Chronic chest disease in Australian aboriginal children. A study was made of the incidence of types of chronic chest disorder in aboriginal children. A high incidence was found, and 83 children with bronchiectasis and 35 with chronic bronchitis are described. All developed the disease at an early age, but, apart from bronchiolitis with dehydration, no specific aetiological factor could be found; tuberculosis, pertussis, and measles, in particular, have been virtually eradicated from this child population. The diseases described flourish in inferior social circumstances, respond to care in good circumstances, but deteriorate again when the children go home. Medical improvement is not maintained unless social circumstances are ameliorated.
\end{abstract}

Chronic chest disease is common in the underdeveloped countries (Webb, 1970), but a few details are known about its incidence or response to treatment. Australian aboriginal children have many of the problems of the underprivilegedmalnutrition, high infant death rates, especially from gastroenteritis, and also a high incidence of chronic chest disease. The latter is the subject of this paper, and the facts found may have relevance to other similar populations.

\section{Background of Patients}

The children studied live in the southern part of the Northern Territory and the northern part of of South Australia (see Fig.). About 1000 children live in forbidding economic, housing, and climatic circumstances (Maxwell and Elliott, 1969). A majority of these children have been examined in the field, or at the Alice Springs Hospital. From them a sample of those with clinical evidence of chronic chest disease was selected for further study in the University unit at the Adelaide Children's Hospital.

\section{Methods of Investigation}

Clinical records of the Northern Territory Medical Service (including aero-medical) were available for all but a few patients. Routine clinical and $x$-ray examinations were supplemented

Received 4 April 1972. by zonal tomography; bronchoscopy and bronchography were performed in a large number (see below). Other investigations to be specified later were done by accepted methods.

Eventually two groups of patients were identified in whom the diagnosis was felt to be established with some certainty. Specifically, these were bronchiectasis ( 83 patients) and chronic bronchitis (35).

\section{Bronchiectasis}

This diagnosis was made in 83 children; by bronchography in $75 \%$, by bronchoscopy alone in $10 \%$, and by $x$-ray and zonal tomography in the remainder.

In the last instance the radiological criteria were peribronchial fibrosis with lobular or lobar collapse. These were also the usual findings in those in whom the diagnosis was confirmed by bronchography.

The disease had its onset at a remarkably tender age (Table I), $60 \%$ being symptomatic by the age of 2 years, and $20 \%$ at 6 months or less. The early onset of symptoms paralleled the age at study, thus $45 \%$ of the group were 4 years or less when investigated and only $11 \%$ were 8 years or more.

Historical factors and bronchiectasis. A chronic productive cough was reported in $84 \%$ and purulent sputum observed in $23 \%$. The incidence of the latter is doubtless higher, as many children in the age-group studied do not expectorate. Bronchiolitis (often several bouts) was the initial 


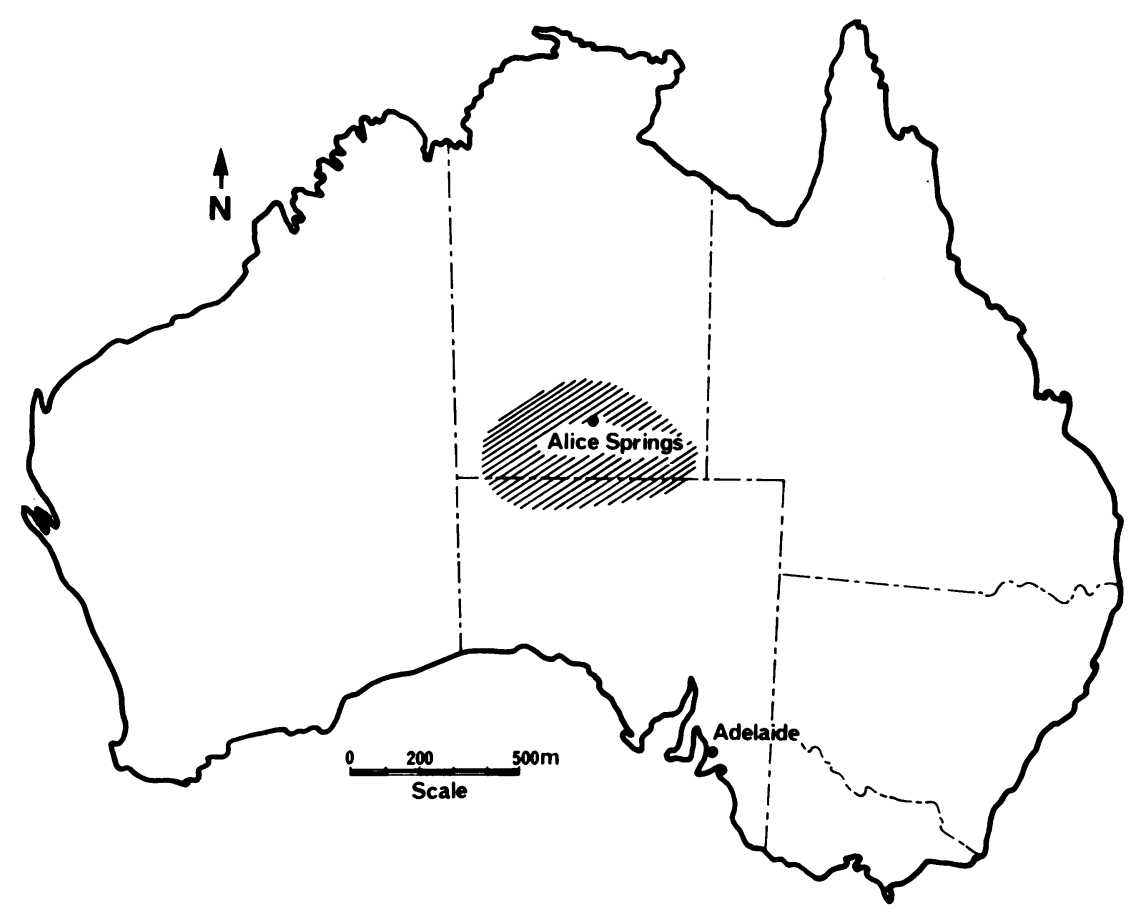

FIG.-The children studied came from the area marked on the map.

TABLE I

Bronchiectasis in 83 Aboriginal Children: Age at Onset of Symptoms

\begin{tabular}{c|c}
\hline Age & $\%$ \\
\hline $0-6 \mathrm{mth}$ & $20 \cdot 5$ \\
$7-12 \mathrm{mth}$ & $24 \cdot 0$ \\
$13-23 \mathrm{mth}$ & $15 \cdot 6$ \\
$2-3 \mathrm{yr}$ & $19 \cdot 3$ \\
$3-4 \mathrm{yr}$ & $7 \cdot 2$ \\
$4-5 \mathrm{yr}$ & $4 \cdot 8$ \\
$5-6 \mathrm{yr}$ & $3 \cdot 6$ \\
O $6 \mathrm{yr}$ & $1 \cdot 2$ \\
Unknown & $3 \cdot 6$ \\
Total $<2 \mathrm{yr}$ & $60 \cdot 1$ \\
\hline
\end{tabular}

illness in $47 \%$, and pneumonia (in 7 children staphylococcal) in 37\%. Recurrent unspecified chest infection was the story in $11 \%$. Coincident with one or more of the above complaints, $55 \%$ of the children had diarrhoea and were dehydrated to a degree requiring intravenous treatment.

Physical signs. These were generally similar to those found in white children with bronchiectasis, but occurring at an earlier age. In contrast to the historical evidence, cough was universal, and after postural drainage $70 \%$ produced purulent sputum. Finger clubbing was found in $24 \%$; chest deformity (Harrison's grooves) occurred in $10 \%$.

The auscultatory signs were of some interest. In contrast to experience in our local white population, $28 \%$ showed no abnormality, even after several examinations. Râles occurred in $37 \%$ and rhonchi in $35 \%$. Bronchial breathing and dullness on percussion were rare $-4 \cdot 8 \%$ and $2 \cdot 4 \%$, respectively.

Malnutrition was common, $67 \cdot 4 \%$ being less than the 10th centile for weight and $56.6 \%$ for height (Tanner, 1958).

Ear, nose, and throat disorders were rife; $71 \%$ of the children had purulent nasal discharge, and opaque maxillary antra were shown on $x$-ray in all. $89 \%$ had chronic suppurative otitis media, onethird being bilateral. Sclerosis of the mastoid air cells was universal in the bilateral group and common in the others.

Other studies. Sweat tests were done on all the children, and were normal, reflecting the rarity or absence of the gene for mucoviscidosis in aborigines (Maxwell, 1971). Serum immunoglobulins were investigated in 76 children; there were no abnormally low values. Increases were recorded 
for $\operatorname{IgA}$ in $63 \%$, for $\operatorname{IgM}$ in $71 \%$, and for $\operatorname{IgG}$ in $94 \%$. Many of the values recorded were 4 to 5 times the normal levels of our laboratory. $\alpha_{1-}$ antitrypsin values were measured in 40 patients; again all were normal.

Spirometry was done in those old enough to co-operate ( $>4$ years) and was repeated at least 3 times. Of the 29 children studied, $52 \%$ gave persistently abnormal results, principally in $\mathrm{FEV}_{1}$ and maximal breathing capacity. Blood-gas analysis was done in 34 children; 17 showed a significant reduction in arterial $\mathrm{Po}_{2} ; p \mathrm{H}$ and $\mathrm{PcO}_{2}$ values were unaffected. Electrocardiographic examinations showed no evidence of right ventricular hypertrophy though 2 children had $x$-ray evidence of right ventricular enlargement. Barium swallows showed no oesophageal reflux in any patient.

Site of bronchiectasis. This is summarized in Table II, which suggests that bilateral disease

TABLE II

Bronchiectasis in 83 Aboriginal Children: Position of Bronchiectasis

\begin{tabular}{l|c}
\hline \multicolumn{1}{c|}{ Position } & $\%$ \\
\hline LLL + RML & $30 \cdot 0$ \\
LLL, RML, RLL & $22 \cdot 9$ \\
LLL alone & $10 \cdot 8$ \\
RLL + LLL & $12 \cdot 0$ \\
RML + RLL & $4 \cdot 8$ \\
RML alone & $6 \cdot 0$ \\
RLL + LUL & $2 \cdot 4$ \\
RLL alone & $2 \cdot 4$ \\
LLL + lingula & $3 \cdot 6$ \\
RML, RUL, LLL & $4 \cdot 8$ \\
\hline
\end{tabular}

was predominant. The distribution of the lesion is, however, not significantly different from that reported in white children (cf. Glauser, Cook, and Harris, 1966).

\section{Chronic Bronchitis}

This diagnosis was made in 35 children in this study. The presenting complaints of this disease were very similar to those of bronchiectasis, the initial symptoms being almost identical (Table III). The age at onset of significant disorder was, however, lower than that in bronchiectasis, thus $66 \%$ of the 35 children had symptoms in the first year, as compared with $45 \%$ of the bronchiectatics.

All 35 children had a productive cough, and purulent sputum was obtained in 32.28 had rhonchi, with associated râles in 7 . Auscultatory signs were absent in 7 of the 35 . Clubbing and chest deformity did not occur in the chronic
TABLE III

Chronic Bronchitis in 35 Aboriginal Children

\begin{tabular}{l|c}
\hline Initial Symptoms & $\%$ \\
\hline Cough & 86 \\
Bronchiolitis & 40 \\
Sputum & 31 \\
Pneumonia (1 staph.) & 43 \\
Recurrent chest infections & 17 \\
Dehydration with 1 of above & 57 \\
Associated disorders & $8 \cdot 5$ \\
(2 congenital heart; & \\
1 hypotonia) & \\
\hline
\end{tabular}

bronchitic children, and sweat tests and $\alpha_{1}$-antitrypsin values were normal. The aberrations of the immunoglobulins were identical to those described for bronchiectasis.

The $x$-rays of this group showed persistent abnormal linear shadows radiating from the hilum. Tomography confirmed the shadows to be undilated bronchi, with peribronchial thickening. These changes were sometimes associated with small areas of parenchymal collapse. Bronchoscopy and bronchography were done in $31 \%$ and $20 \%$, respectively. At bronchoscopy the majority of patients showed reddening of the mucosa, and the amount of secretion present appeared to be increased, and was commonly purulent. The last finding, however, appeared to vary with the duration of prior postural drainage. Bronchography showed no dilatation. The areas of lung commonly involved in the bronchitic process were both lower lobes (28.5\%), left lower and right middle lobes (28.5\%), right middle and right lower lobes (17\%), and in 2 children the disease appeared to be generally distributed. Associated disorders of nutrition and the ear, nose, and throat system did not significantly vary from those recorded for bronchiectasis.

\section{Treatment}

A good diet was supplied, postural drainage and chest percussion were given at least thrice daily, with antibiotic therapy for acute episodes of lung disease. Appropriate ear, nose, and throat therapy was given. The average stay in hospital was about 2 weeks, after which the children were put in a convalescent home where treatment was continued. Each child was discussed with the thoracic surgeon to evaluate the possibility of surgery; of the 83 bronchiectatic children, 32 had operations. A left lower lobectomy was performed in 28 and right middle lobectomy in 2 . In 1 child the right lower lobe was removed, and in another a right pneumonectomy. All patients 
recovered without incident; physiotherapy was continued in the postoperative period. After a period of convalescence, averaging 14 weeks, the children were sent back to their homes in the bush. Physiotherapy was in most cases continued, being done by the mothers, supervised by mission nurses.

\section{Results of Treatment}

This was assessed after hospital and convalescent home treatment, and again after return home. Improvement of the chest condition was thought to have occurred if the child no longer coughed spontaneously or on posturing, and if purulent sputum was no longer obtained. These simple criteria were the only ones available in all circumstances, though follow-up $x$-rays were obtained for about $70 \%$ of the children.

Generally speaking, the response in good surroundings (hospital, convalescent home) was gratifying. Nutrition improved, and symptoms subsided. The improvement in nutrition was not, however, related to improvement of the chest condition, as it was seen in other disease states treated in the same environment. As Table IV

TABLE IV

Results of Treatment

\begin{tabular}{|c|c|c|}
\hline & $\begin{array}{c}\text { Bronchiectasis } \\
(\%)\end{array}$ & $\begin{array}{c}\text { Chronic } \\
\text { Bronchitis (\%) }\end{array}$ \\
\hline $\begin{array}{l}\text { Response to medical treatment } \\
\text { Short-term } \\
\text { Improved } \\
\text { Unchanged } \\
\text { Deteriorated }\end{array}$ & $\begin{array}{l}74 \\
26 \\
-\end{array}$ & $\begin{array}{l}74 \\
26 \\
-\end{array}$ \\
\hline $\begin{array}{l}\text { Long-term } \\
\text { Improved } \\
\text { Unchanged } \\
\text { Deteriorated } \\
\text { Death }\end{array}$ & $\begin{array}{r}19 \\
44 \\
34 \\
2\end{array}$ & $\begin{array}{l}26 \\
55 \\
19 \\
-\end{array}$ \\
\hline $\begin{array}{l}\text { Response to surgical treatment } \\
\text { (No. = 32) } \\
\text { Short-term } \\
\text { Improved } \\
\text { Unchanged }\end{array}$ & $\begin{array}{r}94 \\
6\end{array}$ & \\
\hline $\begin{array}{l}\text { Long-term } \\
\text { Improved } \\
\text { Reverted to preoperative state } \\
\text { Deteriorated }\end{array}$ & $\begin{array}{l}38 \\
31 \\
31\end{array}$ & \\
\hline
\end{tabular}

shows, however, after returning home there was a steady erosion of the improvement gained in Adelaide. This applies whether the children were treated medically or surgically. Deterioration was slower with the latter group, perhaps because they originally had less extensive bronchiectasis- bilateral disease being normally considered a contraindication to surgery.

\section{Comment}

There is little to say about aetiology; the inoculation campaigns among the children have practically eradicated tuberculosis, pertussis, and measles -each formerly thought to be relevant to bronchiectasis (Jolly, 1968). It seems that bronchiolitis is the most important precipitating factor, especially if it coincides with dehydration. The combination of local and general dehydration may well contribute to a higher incidence of pulmonary collapse, with consequent bronchiectasis. In general then, the precipitating factors are those described for white Australian children (Williams and O'Reilly, 1959), but for the rather high incidence of staphylococcal pneumonia and the absence of cystic fibrosis.

As noted in the tables, coincident malnutrition and ear, nose, and throat suppuration is common. Each is, however, associated rather than causal. Thus malnutrition is common-up to $25 \%$ of an aboriginal community may be in the 3 rd or lower centile, which is a far higher incidence than of chronic lung disease. The same argument applies to ear, nose, and throat disease-the incidence within a group of aboriginal children was $69 \%$ (Maxwell and Elliott, 1969), but the incidence of chronic chest disease was much lower. Similarly, I have examined many chronic sufferers from ear, nose, and throat disorders who had neither clinical nor $x$-ray evidence of chronic lung disease. This opinion of coincidence rather than causation agrees with the views of Davison (1944) who studied bronchiectasis in white children.

The results do not support any racial or other predisposition to chronic chest infection. The most obvious association would be that of overcrowding with constant cross-infection. Certainly in a group of 40 fullblood aboriginal children reared in good homes in Adelaide, chronic chest infection does not exist. Similarly bronchiolitis, though common in white children in Adelaide, is seldom followed by chronic pulmonary disease. The major difference between the two racial groups lies in the better social conditions of the whites. Thus most of these aboriginal children live in semidesert conditions in rude shelters called 'wurlies' or 'humpies'. These have a framework of mulga-wood covered with old tarpaulin, blankets, or other textiles. The average floor area is $6 \mathrm{ft}$ by $6 \mathrm{ft}$ and the height is about $4 \mathrm{ft}$. This space is usually occupied by 2 adults, 3 to 4 children, and numerous dogs. The whole gives 
an admirable setting for cross-infection and constant reinfection.

Certain practical points emerge from this study which may be helpful to those encountering similar populations; thus, absence of auscultatory signs is no proof that chronic lung disease is absent. Accordingly, $x$-rays are necessary. These cannot normally be taken in the field so that a simple mode of selection is needed. The best test is to get the child to cough -if it is loose, he is a candidate for chronic chest disease. If he coughs up pus, then the diagnosis is almost certain.

The amount of money and effort spent in treating these children is very great and while improvement can be obtained in good social circumstances, deterioration occurs when they return to the 'wurlie'. There is little hope of maintaining clinical improvement even with medical treatment in the field, unless social circumstances improve. The elimination of pertussis, measles, and tuberculosis is not necessarily followed by a decline in chronic chest disease.

I am greatly obliged to $\mathrm{Mr}$. Howard Brown, thoracic surgeon to the Adelaide Children's Hospital, for his constant interest in, and help with, these children, and to Dr. W. A. Langsford, Commonwealth Director of Health, Northern Territory, for his co-operation.

\section{REFERENCES}

Davison, F. W. (1944). Does chronic sinusitis cause bronchiectasis ? Annals of Otology, Rhinology and Laryngology, 53, 849.

Glauser, E. M., Cook, C. D., and Harris, G. B. C. (1966). Bronchiectasis: a review of 187 cases in children with follow-up pulmonary function studies in 58. Acta Paediatrica Scandinavica, 55, Suppl. 165.

Jolly, H. (1968). Diseases of Children, 2nd ed., p. 340. Blackwell, Oxford.

Maxwell, G. M. (1971). Rarity of mucoviscidosis in Australian aborigines. (Letter). Lancet, 1, 1190.

Maxwell, G. M., and Elliott, R. B. (1969). Nutritional state of Australian aboriginal children. American fournal of Clinical Nutrition, 22, 716.

Tanner, J. M. (1958). The evaluation of physical growth and development. In Modern Trends in Paediatrics (Second Series), p. 325. Ed. by A. Holzel and J. P. M. Tizard. Butterworth, London.

Webb, J. K. G. (1970). Diseases of Children in the Subtropics and Tropics, 2nd ed., p. 233 et seq. Ed. by D. B. Jelliffe. Arnold, London.

Williams, H., and O'Reilly, R. N. (1959). Bronchiectasis in children: its multiple clinical and pathological aspects. Archives of Disease in Childhood, 34, 192.

Correspondence to Professor G. M. Maxwell, Department of Paediatrics, University of Adelaide, Adelaide Children's Hospital, North Adelaide, 5006, South Australia. 